\title{
A Cartografia Social como Processo Organizativo de Visibilidade e Mobilização Social: relato da experiência com moradores em áreas sujeitas a inundação na cidade de Guarapuava-PR, entre 2015 - 2016
}

Social Cartography as an Organizational Process of Visibility and Social Mobilization: report of the experience with residents in areas subjected to flood in Guarapuava-PR, between 2015 - 2016

La Cartografía Social como Proceso Organizacional de Visibilidad y Movilización Social: relato de la experiencia con moradores en áreas sujetas a inundación en la ciudad de Guarapuava - PR, entre 2015 - 2016

\author{
Leonides Ferreira Silva ${ }^{1}$ \\ Marquiana de Freitas Vilas Boas Gomes ${ }^{2}$
}

RESUMO: A apropriação social da cartografia, por meio da democratização do acesso à informação, aos mapas e processos tecnológicos, tem contribuído para as lutas sociais, das quais a cartografia social é um exemplo. Pautada no envolvimento direto dos sujeitos sociais, potencializa a autoafirmação dos sujeitos bem como sua visibilidade, mobilização e reivindicação dos direitos territoriais. Nesta, os sujeitos sociais, organizados em coletivos, tais como comunidades tradicionais ou associações de bairro, decidem o quê e como representar-se, por meio do diálogo e da troca de experiências entre o conhecimento local e o técnico. Com o intuito de contribuir com a reflexão sobre a cartografia social em ambientes urbanos, neste artigo apresenta-se a experiência realizada com moradores do bairro Vila Carli, vítimas das inundações do rio Cascavel, no ano de 2014, na cidade de Guarapuava, estado do Paraná. A abordagem metodológica é qualitativa, buscando descrever e registrar o processo que culminou com a produção de um fascículo sobre o bairro, problematizando os desastres naturais, suas consequências e as demandas dos moradores. Os resultados apontaram para a importância da cartografia social como um processo organizativo, de visibilidade e mobilização social, na medida em que envolve efetivamente os sujeitos sociais suscetíveis à vulnerabilidade ambiental na discussão da/na cidade.

PALAVRAS-CHAVE: Cartografia social; Vulnerabilidade; Mobilização.

ABSTRACT: The social appropriation of the cartography, by the democratization of access to information, maps and technologies processes, it has been helping for social struggles, of which the

\footnotetext{
${ }^{1}$ Universidade Estadual do Centro Oeste - UNICENTRO. Rua Simeão Camargo Varela de Sá, 03 Vila Carli | CEP 85040-080. leonides-silva@hotmail.com.

2 Universidade Estadual do Centro Oeste - UNICENTRO. Rua Simeão Camargo Varela de Sá, 03 Vila Carli | CEP 85040-080. marquiana@gmail.com.
} 
A Cartografia Social como Processo Organizativo de Visibilidade e Mobilização Social: relato da...

social cartography is an example. Based on the direct involvement of social subjects, it empowers the self-affirmation of the subjects as well as their visibility, mobilization and claim of territorial rights. In this, social subjects, organized in collectives, such as traditional communities or neighborhood associations, decide what and how to represent themselves, through dialogue and the exchange of experiences between local and technical knowledge. The goal of contributing with the reflection about the social cartography in urban areas, in this paper, it brings the experience made with Neighborhood's residents Vila Carli, victims of Cascavel River's flood in 2014, in Guarapuava-PR Brazil. The methodology is qualitative, searching out for describe and register the process that peaked with the production of a fascicle about the neighborhood, discussing the natural disasters, its consequences and the demands of the residents. The results pointed to the social cartography importance as an organizational process, of visibility and social mobilization, as far as involves effectively the susceptible social subjects to an environmental vulnerability in the discussion of the/in the city.

KEYWORDS: Social cartography; Vulnerability; Mobilization.

RESUMEN: La apropiación social de la cartografía, por medio de la democratización del acceso de la información, de los mapas y procesos tecnológicos, tiene contribuido para las luchas sociales, de las cuales la cartografía social es un ejemplo. Pautada en el envolvimiento directo de los sujetos sociales, potencializa la autoafirmación de los sujetos bien como su visibilidad, movilización y reivindicación de los derechos territoriales. En esta, los sujetos sociales, organizados en colectivos, tales como comunidades tradicionales o asociaciones de barrios, deciden que es como representarse, por medio de diálogo y de la troca de experiencias entre el conocimiento local y el técnico. Con el intuito de contribuir con la reflexión sobre la cartografía social en ambientes urbanos, en este artigo, presentase la experiencia realizada con moradores del barrio Vila Carli, víctimas las inundaciones del rio Cascavel, en el año de 2014, en la ciudad de Guarapuava, estado del Paraná. La abordaje metodológica es cualitativa, buscando describir y registrar el proceso que culminó con la producción de un fascículo sobre el barrio, problematizando los desastres naturales, sus consecuencias y las demandas de los moradores. Los resultados apuntaron para la importancia de la cartografía social como un proceso organizativo, de visibilidad y movilización social, en la medida en que envuelve efectivamente los sujetos sociales susceptibles a la vulnerabilidad ambiental en la discusión de la ciudad.

PALABRAS CLAVES: Cartografía social; Vulnerabilidad; Movilización.

\section{INTRODUÇÃO}

Cada vez mais o acesso aos produtos cartográficos (mapas, imagens e cartas) tem se democratizado, com isso a possibilidade de apropriação social da cartografia tem contribuído para as lutas sociais. Este trabalho problematiza esta questão no que diz respeito à cartografia social.

A cartografia social é um processo de mapeamento com envolvimento direto dos sujeitos sociais, com vistas à autoafirmação e reivindicação dos direitos no/do território. Esses sujeitos decidem o quê e como representar-se, representação esta que exige, por parte dos envolvidos (população, técnicos e/ou pesquisadores), a troca de experiência entre o conhecimento técnico e o saber local, por meio do diálogo e da valorização de ambos, 
sem sobreposição e/ou hierarquização de um ao outro. Desse modo, a cartografia social é um processo organizativo, de visibilidade e mobilização social.

Neste artigo objetiva-se apresentar a experiência com cartografia social realizada na cidade de Guarapuava, no Paraná, com moradores do bairro Vila Carli, vítimas das inundações no rio Cascavel, no ano de 2014 (SILVA, 2016). O rio atravessa a cidade de noroeste a sudoeste, passando por diferentes bairros. A cidade tem mais de $80 \%$ de sua área assentada sobre a Bacia Hidrográfica do Rio Cascavel (GOMES, 2012).

Por um lado, a ocupação e uso do solo associadas às características do relevo contribuem para explicar os fatores que potencializam os alagamentos e inundações no bairro. Por outro lado, o processo de produção da cidade e a desigualdade social são fatores atrelados e que explicam a ocupação das planícies de inundação do rio Cascavel (GOMES, 2014). Uma parte dos moradores está assentada nesta área desde o início do processo de crescimento urbano, em 1960, outra parte chegou com a ampliação e adensamento urbano, a partir de 1980. O crescimento da população urbana se deu, principalmente, pelo êxodo rural de meeiros, posseiros e trabalhadores das serrarias que também se concentravam no campo (GOMES, 2012).

Silva (2016) explica que a pressão por moradia na cidade, sem o planejamento adequado pelo poder público, fez com que emergissem um conjunto de interesses privados, sobretudo de proprietários fundiários urbanos (algumas áreas eram chácaras) e proprietários imobiliários. Com isso, houve a transformação de espaços extensos de terra, no entorno do perímetro urbano original, em loteamentos para moradia, cuja valorização foi garantida, pela demanda, pela infraestrutura oferecida ou pela proximidade do centro da cidade.

O campo de forças estabelecido entre os agentes de produção do espaço urbano (em Guarapuava são os proprietários fundiários, imobiliários e a população recém-chegada do campo) configurou a organização da cidade naquele período. A cidade é a expressão material desse processo (CORRÊA, 1995). Ou seja, se por um lado a produção é coletiva, por outro, sua apropriação é seletiva e desigual (GOMES, 2010).

O preço da terra urbana cresceu substancialmente, sendo menor nas áreas de risco. Com isso, sem restrições por parte do poder público e com a ausência de uma política de planejamento urbano, deu-se início a ocupação das áreas sujeitas à inundação no rio Cascavel.

Desde a ocupação da área houve vulnerabilidade constante aos desastres naturais, entendidos aqui como processos ambientais que resultam em danos materiais e/ou humanos (VESTENA, 2014, 2016), os quais fragilizam as famílias que convivem com a insegurança a cada evento daqueles. A chuva intensa no ano de 2014 provocou uma das 
A Cartografia Social como Processo Organizativo de Visibilidade e Mobilização Social: relato da...

maiores inundações do rio Cascavel, com mais estragos e vítimas do que nos anos anteriores.

É nesse cenário que um conjunto de ações do poder público começou a ser realizada na área, envolvendo dentre elas a delimitação da planície de inundação e algumas iniciativas de remoção e/ou ajuda às famílias vítimas do desastre. Neste artigo, apresentamse os resultados da pesquisa que acompanhou esse processo, e destaca-se, particularmente, a experiência com a cartografia social dos desastres naturais no bairro.

O texto está dividido em três partes. Na primeira, faz-se um esboço sobre a cartografia social, as características e princípios que a orientam. $\mathrm{Na}$ segunda, descrevem-se os procedimentos metodológicos da pesquisa e, na terceira e última parte, apresenta-se a formação do bairro, o histórico de ocupação das áreas sujeitas à inundação e os fatores que potencializam os desastres naturais, assim como a percepção dos moradores sobre esses processos.

\section{CARTOGRAFIA SOCIAL: PROCESSO EDUCATIVO E DE ORGANIZAÇÃO SOCIAL}

$\mathrm{Na}$ cartografia social está imbricado o reconhecimento da importância dos saberes dos sujeitos sociais sobre o seu território, por isso integra-os diretamente no processo de representação. Por meio de reuniões e oficinas de trabalho, incorpora a produção dos mapas, os depoimentos, os debates coletivos entre as pessoas das comunidades, a produção de croquis e os registros fotográficos. Além disso, outros documentos podem servir de apoio como relatórios, pesquisas de campo e entrevistas. Ou seja, compreende-se que o mapa em si é limitante para representar a realidade e, por isso, envolve outras linguagens, em um processo de construção dialógico e coletivo, potencializando aos sujeitos um processo político de autoafirmação e reivindicação dos seus direitos. Portanto, não se pode confundir cartografia social com a cartografia convencional.

Lobatón (2009) destaca algumas particularidades da cartografia social em comparação à convencional, tais como: a) o território é representado com variáveis importantes para a comunidade em detrimento dos interesses do Estado-Nação e/ou instituição; b) utiliza-se metodologias qualitativas; c) o posicionamento político se sobrepõe à pretensa imparcialidade; d) representa-se o espaço percebido, concebido e vivido e não apenas o espaço euclidiano; f) em regra dedica-se mais tempo, pois o mais importante é o "processo" do que o "produto"; g) os processos de sistematização são mais incipientes do que na convencional e carecem de um sistema de documentação; e h) a escala é detalhada e definida pelo nível de participação. 
Porém, embora em consonância com os interesses dos grupos sociais na luta pelos direitos do território, métodos participativos também podem ser usados a favor de grupos externos às comunidades, como estratégia de dominação e apropriação dos "saberes" locais. Sobre isso, Acselrad et al. (2013) afirma que, se por um lado, a dominação pode ser reforçada por meio da apropriação do conhecimento dos locais, por outro, pode instabilizála, uma vez que estes mesmos processos podem criar estratégias de organização coletiva e de visibilidade para firmar direitos territoriais e, assim, construir formas de resistência e autoafirmação.

Os processos de cartografia social têm se espalhado pelo Brasil, sobretudo no campo. Na região Norte há experiências com as populações tradicionais extrativistas, ribeirinhos, agricultores familiares e indígenas, como forma de enfrentamento à construção de novas usinas hidrelétricas, à grilagem de terras, ao desrespeito aos limites das terras indígenas e às áreas de preservação ambiental. Na região Nordeste destaca-se as cartografias das comunidades pesqueiras litorâneas, agricultores familiares, quebradeiras de coco babaçu, cipozeiros, indígenas e quilombolas opondo-se aos empreendimentos de energia eólica, resorts, carcinicultura (viveiros de criação de camarões), mineração, obras hídricas, dentre outros. Na região Sul e Sudeste são importantes as ações dos caiçaras e quilombolas, contra a perda de territórios (GORAYEB, 2014).

No entanto, na cidade, os processos são mais reduzidos, mas nos últimos cinco anos têm crescido como um instrumento de luta importante para as populações em áreas de risco urbano (por exemplo, no Rio de Janeiro, a Maré [complexo de favelas] assim como, em Fortaleza, a favela Poço da Draga), comunidades e associações indígenas na cidade de Manaus e em Belém (GORAYEB, 2014).

Essas experiências com vistas ao fortalecimento das lutas e construção dos processos organizativos são engajadas no diálogo entre as comunidades, e os pesquisadores e/ou técnicos envolvidos. Isso porque "[...] a cartografia social tem como função social fazer valer as reivindicações sobre territórios e seus recursos por parte das populações locais" (ACSELRAD, 2010, p. 9).

Para isso, a interação entre os sujeitos do processo fortalece a construção de estratégias comuns, mesmo nas especificidades de cada um dos movimentos sociais que compõem a população representada, permitindo que a cartografia social se consolide enquanto um processo de mobilização social e de fortalecimento da identidade coletiva, possibilitando a existência das relações entre a legitimidade dos sujeitos e seus efeitos de poder e existência sobre o território. Ou seja, a comunidade, até então excluída dos processos de mapeamento, passa a exercer uma função vital na sua organização (VANDRESEN, 2014). 
A Cartografia Social como Processo Organizativo de Visibilidade e Mobilização Social: relato da...

Porém, considerando que os instrumentos para cartografar o território predominam nas mãos do Estado, é necessário criar mecanismos para que os grupos sociais vulneráveis também possam elaborar suas próprias representações, com vistas à sua organização e à defesa dos seus interesses. O apoio técnico a esses grupos é fundamental. Acselrad e Viégas (2013, p. 21), ao tratar do conhecimento técnico e popular, afirmam que:

$\mathrm{Na}$ elaboração do mapa, o reconhecimento do saber tradicional nem sempre é evidente. É a partir do diálogo de saberes que o conhecimento local pode se expressar. A interação entre sujeitos com o conhecimento técnico e sujeitos com o conhecimento tradicional deve ser objeto de reflexão por parte dos pesquisadores do processo cartográfico e seus métodos, de modo a se alcançar o diálogo entre técnicas e saberes e evitar a imposição de um sobre o outro, ou ainda que se excluam mutuamente. Isso implica na necessidade de que os sujeitos do conhecimento técnico construam junto com as comunidades e suas autoridades étnicas as estratégias do processo cartográfico.

Um aspecto importante sobre a elaboração dos mapas, por exemplo, é saber "quem mapeia quem". Em alguns casos, são atores externos, como ONGs, entidades ambientalistas, antropólogos, membros de lgrejas, e associações de moradores, que realizam o convite para a comunidade para que elas venham a participar e se envolver na elaboração do mapeamento. Os próprios sujeitos têm questionado se devem participar de mapeamentos auxiliados por terceiros, em processos nos quais acham que não vão ter autonomia. Os atores, cada vez mais, entendem que eles próprios devem conduzir o processo de mapeamento de seus territórios (ACSELRAD et al., 2013).

De qualquer modo, a cartografia social surge como uma importante ferramenta de empoderamento do cidadão frente ao monopólio do Estado. Ela pode ser considerada como um "processo" e não uma "técnica" de representação em si. Parte do princípio da autorrepresentação, implicando na forma como o sujeito concebe o espaço apropriado, seus interesses e os conflitos vivenciados. Assim, por meio da percepção, do registro fotográfico, do texto, do croqui e do mapa, coletivamente os sujeitos representam o território. Desse modo, a cartografia social, não se restringe a localizar e distribuir os elementos do espaço representado, mas sua função é de expressar, por meio da representação, a teia de relações conflituosas do território (NOVA CARTOGRAFIA SOCIAL..., 2015).

Trata-se de um processo educativo no/do território. É neste contexto que se insere a experiência realizada com moradores do bairro Vila Carli, na cidade de Guarapuava, PR, entre 2015 e 2016, apresentada na sequência deste texto. 


\section{PROCEDIMENTOS METODOLÓGICOS}

O processo de realização da cartografia social com as vítimas dos desastres naturais em Guarapuava-PR consistiu em um conjunto de ações de pesquisa e interação entre os pesquisadores e os moradores do bairro Vila Carli. Para tanto, combinou-se diferentes instrumentos de coleta e análise de dados, tais como: ações em parceria com o poder público local, trabalhos de campo, análise documental, elaboração de banco de dados, entrevistas, oficinas e produção de fascículo.

A produção do fascículo foi resultado das oficinas de cartografia social e ocorreram no próprio bairro, no salão da Paróquia Domingos Sávio, precedidas de autorização de uso de depoimentos e imagens pelos participantes. Nas oficinas foi realizada a apresentação do projeto entre os participantes, moradores da Vila Carli e pesquisadores, a definição dos objetivos e como seria a organização do fascículo. Por meio de atividades coletivas, os participantes fizeram uma reflexão sobre o bairro, os aspectos positivos e negativos do cotidiano e sua relação com os desastres naturais.

Outra atividade consistiu na reflexão sobre como solucionar os problemas identificados e qual a visão de cada um sobre as possibilidades de mudanças e intervenções necessárias para solucionar as questões referentes às moradias nas áreas sujeitas à inundação bem como a redução dos riscos aos desastres. Ao realizar o reconhecimento dos equipamentos coletivos e sobre a infraestrutura do bairro, os moradores narraram e explicaram os conflitos sociais e ambientais vivenciados.

Identificadas as questões comuns e específicas, por meio da manipulação de imagens e mapas, os moradores localizaram suas residências, as igrejas, as escolas, os postos de saúde, os locais para as práticas esportivas, os estabelecimentos comerciais etc., e também elaboraram croquis, com desenhos e textos (Figura 1). Nessas atividades, observou-se 0 que já apontava Ascrelrad e Viégas (2013, p. 24), que:

O processo de construção do mapa possui um grande potencial de visibilizar o conhecimento que, muitas vezes, está guardado mais em algumas pessoas do que em outras - está nos caçadores, nos pescadores, nos mais velhos, etc. $E$ no momento em que os grupos se reúnem dentro desse processo, o conhecimento entra em efervescência. Sendo assim, a cartografia cria um ambiente de fala, de discussão, onde os grupos quebram silêncios e buscam compreender a si mesmos, o que gera efeitos políticos imediatos.

Sistematizadas as informações das ações realizadas com o poder público, das entrevistas, dos trabalhos de campo e das oficinas, os dados foram compilados, com os quais se produziram mapas e reuniram-se os textos a partir dos depoimentos dos 
A Cartografia Social como Processo Organizativo de Visibilidade e Mobilização Social: relato da...

moradores, resultando na primeira versão do fascículo. O resultado foi discutido entre os moradores para avaliação e mudanças necessárias.

Figura 1 - Etapas das Oficinas de Cartografia Social com moradores do bairro Vila Carli

a) Debate coletivo

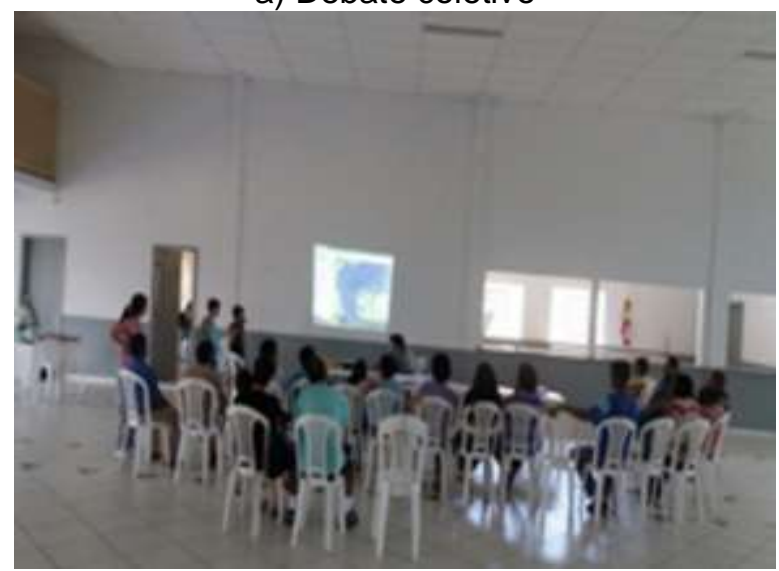

c) Elaboração de croquis

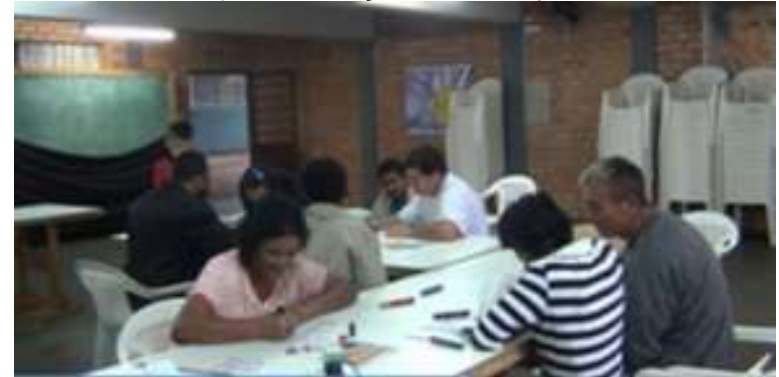

b) Localizando-se na carta

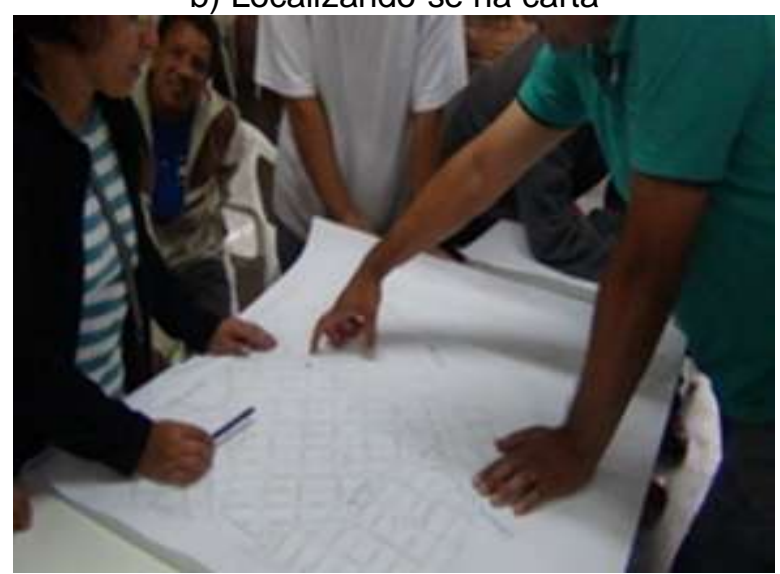

d) Socialização no grupo

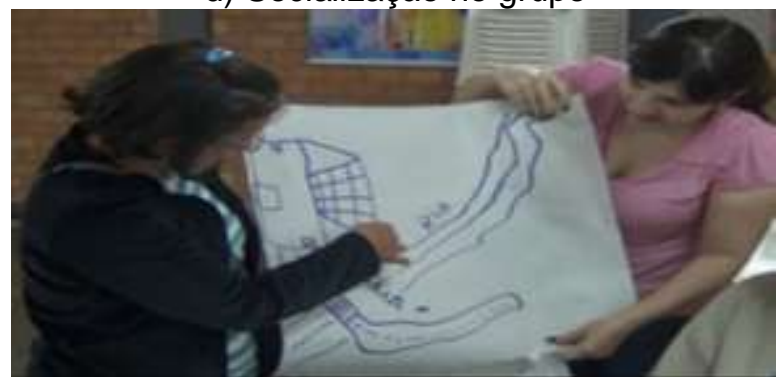

Fonte: Organizado pelos autores com base em Silva (2016) e Oficinas de cartografia social (2015, 2016).

O fascículo reúne sumariamente o histórico do bairro, os desastres decorrentes das inundações e suas consequências às famílias atingidas, assim como suas reivindicações. É um documento no qual estão registrados o resultado das discussões no "processo" da cartografia social. As discussões presentes estão detalhadas na sequência deste artigo.

\section{DESASTRES NATURAIS DECORRENTES DOS ALAGAMENTOS E INUNDAÇÕES NA VILA CARLI: O CONTEXTO E O PROCESSO DE CARTOGRAFIA SOCIAL}

O bairro Vila Carli está localizado entre as coordenadas 25을 $21^{\prime} 36^{\prime \prime}$ e $25^{\circ} 23^{\prime} 04^{\prime \prime} \mathrm{N}, 51^{\circ}$ 28'54" e 51ㅇ 30 '28'W (Figura 2) e tem uma área de 4.35 quilômetros quadrados, com 2.827 lotes, destes, 82 , ou 27\% (2.326) estão edificados, dados da Prefeitura Municipal de Guarapuava (GUARAPUAVA, 2016). Possui 9.279 habitantes, 6,54\% habitantes do total de 141.957 da população urbana do distrito sede de Guarapuava (IBGE, 2011). O bairro é formado por sete loteamentos, conforme Quadro 1.

Observa-se no Quadro 1 que somente dois desmembramentos, dos oito construídos nos anos 1980 e 1990, os loteamentos Airton da Rocha Penteado e Jardim Santa Inês, 
possuem aprovação de área pela Prefeitura Municipal de Guarapuava e nem mesmo o Loteamento Municipal Paz e Bem, construído pela própria prefeitura para atender famílias que viviam em áreas de inundação na cidade, está regularizado.

Figura 2 - Expansão territorial da ocupação urbana no bairro Vila Carli Década de 1960 Década de 1970 Década de 1980

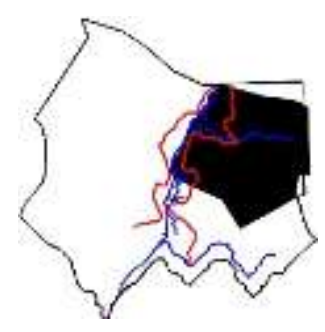

Rio Cascavel

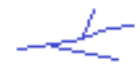

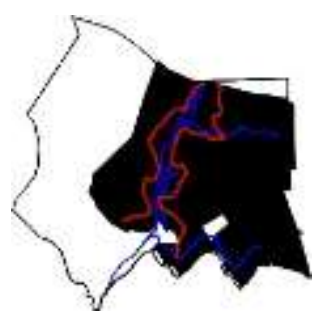

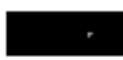

Áreas Ocupadas

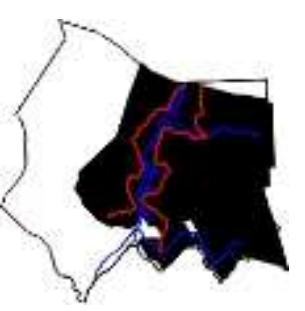

Legenda:

Fonte: Organizado pelos autores a partir de Guarapuava (2016).
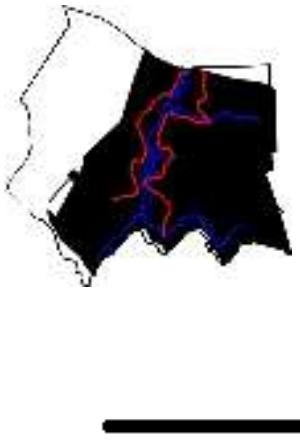

Limite do bairro

Quadro 1 - Loteamentos que formam o bairro Vila Carli

\begin{tabular}{|l|r|r|}
\hline Loteamento & Ano de Implantação & Aprovação \\
\hline Vila Carli & Década de 1960 & Não \\
\hline Aparício Klein & 1975 & Não \\
\hline Vila Paraná & 1975 & Não \\
\hline Dona Ângela & 1976 & Não \\
\hline Vila Helena & 1976 & Não \\
\hline Jardim Santa Inês & 1980 & Sim \\
\hline Gleba Ailton da Rocha Penteado & 1990 & Sim \\
\hline Municipal Paz e Bem & 1998 & Não \\
\hline
\end{tabular}

Fonte: Organizado pelos autores a partir de Guarapuava (2016).

O desmembramento pertencente a Ailton da Rocha Penteado foi efetuado em vários momentos, e em diversos protocolos na Prefeitura Municipal de Guarapuava, de 1990 a 1994. A cada venda realizada o proprietário aprovava o parcelamento e registrava no Cartório de Registro de Imóveis (CRI), enquanto o Jardim Santa Inês foi aprovado pelo decreto 011/1980, em 09/01/1980, e o Loteamento Municipal Paz e Bem encontra-se em fase de regularização fundiária porque foi implantado e urbanizado em área do Ministério da Defesa. O bairro possui 508 unidades de lotes, todas ocupadas por famílias oriundas de áreas inundadas do Jardim das Américas, Vila São Vicente e Vila Carli. Porém, após a realocação das famílias desses bairros para o bairro Paz e Bem, outras famílias ocuparam as mesmas áreas nos respectivos bairros.

Entre 1950 e 1980 a população urbana ultrapassou a rural, quando a estagnação das serrarias, a modernização do campo e a integração do município à economia nacional, consolidaram o êxodo rural e o processo de urbanização em Guarapuava (GOMES, 2012). 
A Cartografia Social como Processo Organizativo de Visibilidade e Mobilização Social: relato da...

Em 1980, a população urbana representava 68\% do total da população e em 2010 este índice foi para 91,43\%. Ou seja, dos 167.328 habitantes do município, 152.993 se concentravam na área urbana, sendo 141.957 habitantes no distrito sede, e 11.036 habitantes nos núcleos urbanos de quatro distritos do município: Palmeirinha, Guairacá, Guará e Entre Rios. Essa urbanização intensa foi desordenada, pois não foi acompanhada de políticas públicas equivalentes para garantir as condições de habitabilidade adequadas a toda população e, consequentemente, causou graves desigualdades sociais e danos ambientais.

Essa expansão urbana de Guarapuava se deu por meio de um processo de adensamento do quadro urbano primitivo por uma população de maior renda, e o deslocamento gradativo da população de menor renda para os espaços periféricos, alguns deles são áreas suscetíveis à inundação e sem infraestrutura (RIGHI, 2003). Com o aumento da demanda por terra urbana, os proprietários de chácaras e investidores imobiliários parcelaram glebas rurais para fins de loteamento, mas sem a implantação da infraestrutura e regularização. Dividia-se toda a gleba em lotes e ruas, parcelando e comercializando até mesmo as áreas inundáveis. Conforme relatos nas oficinas de cartografia, o primeiro loteamento não tinha nem ruas abertas, nem energia elétrica e água.

Quando eu vim morar aqui, há 40 anos, não tinha nada. As poucas casas eram bem longe uma das outras. Não tinha nem rua aberta, era só "carreiro". Não tinha rede elétrica, só lampião, não tinha água encanada. Tive que fazer poço. Lá onde tem a igreja Dom Bosco, era uma capelinha bem pequena. Hoje é diferente. Tem toda a infraestrutura ${ }^{3}$.

Em 1960, quando se deu início ao parcelamento da Gleba Chácara Dr. Laranjeiras para a implantação do loteamento Vila Carli, a dimensão dos lotes era de 600 metros quadrados, nos anos seguintes aumentou-se o parcelamento com lotes de 400 e 250 metros quadrados, com isso, além da ampliação da área de ocupação, a mesma foi adensada (Figura 2) (GUARAPUAVA, 2016).

A infraestrutura instalada posteriormente, como a rede de energia elétrica, de água, de esgoto e pavimentação, foi realizada com investimentos do poder público e dos moradores na forma de impostos ou taxa de contribuição para melhorias. Essas transformações, somadas à instalação de equipamentos urbanos coletivos, como o Centro de Desenvolvimento Tecnológico de Guarapuava, CEDETEG, atualmente campus da Universidade Estadual do Centro-Oeste - UNICENTRO, escolas, posto de saúde, creche, etc., foram fatores importantes para valorização dos lotes e moradias no bairro. Todavia, o

\footnotetext{
${ }^{3}$ João Mendes de Castilho, 2015, depoimento na oficina de cartografia social.
} 
uso e ocupação no bairro não foram acompanhados de restrições às ocupações das áreas sujeitas à inundação pelo Rio Cascavel.

A planície de inundação do Rio Cascavel ocupa 13,02\% (566.450,78 metros quadrados) da área do bairro. Em relação a essas áreas os moradores relatam que os agentes imobiliários divulgavam os lotes durante a época de estiagem e como eram planos e a preços acessíveis, muitos compravam sem saber que estavam sujeitos às inundações.

Além da ocupação das planícies de inundação do Rio Cascavel, outros fatores potencializam os desastres naturais na localidade. Atualmente, $82,27 \%$, do total dos lotes são edificados (GUARAPUAVA, 2016) e, com isso, aumenta a impermeabilização do solo, assim reduz a infiltração da água das chuvas e contribui para que o escoamento seja mais rápido e em maior volume.

Conforme Gomes (2014) é importante compreender que as inundações são fenômenos naturais dos regimes dos rios, mas podem ser potencializadas conforme o uso e ocupação do solo na cidade. São transbordamentos das águas de um canal de drenagem, atingindo as áreas marginais (planície de inundação ou área de várzea).

Elas podem ser classificadas em graduais ou bruscas, ou seja, lentas ou rápidas. Nas graduais o transbordamento do rio é lento e é mais fácil tomar medidas de precaução (GOERL; KOBIYAMA, 2005). As bruscas acontecem de forma rápida, deixando pouco tempo para a tomada de decisões. A maior parte das inundações bruscas é ocasionada em decorrência de chuvas convectivas regionais ou locais. Popularmente são chamadas de enxurradas (CANHOLI, 2005). Segundo Gomes (2014, p. 47):

Geralmente as inundações bruscas estão associadas a um tempo de concentração de até 6 horas. No entanto, este tempo é muito variável, pois dependem de outros fatores além da quantidade da chuva e da resposta do canal fluvial, como chuva antecedente, relevo, uso e ocupação do solo, impermeabilização, quantidade de rios retificados e/ou canalizados, cobertura vegetal e outros.

Outros condicionantes também são importantes, pois, conforme explicam Dias-Oliveira e Vestena (2013, p. 33), "[...] os significativos volumes de chuvas principalmente nos meses de verão têm cada vez mais causados problemas à população em decorrência da impermeabilização, canalização e compactação do solo na Bacia do Rio Cascavel".

A pluviosidade em Guarapuava é alta, conforme o Sistema de Informações Hidrológicas (SIH) do Instituto das Águas do Paraná (AGUASPARANA), no período de 1976 a 2015 a pluviosidade média foi de 2.005,5 milímetros. Só nos eventos dos dias 06 e 07 de junho de 2014 choveu 414 milímetros. Essa precipitação foi considerada como tempestade local/convectiva, com chuvas intensas (GUARAPUAVA, 2014a). 
A Cartografia Social como Processo Organizativo de Visibilidade e Mobilização Social: relato da...

Outro aspecto diz respeito ao solo nas planícies de inundação do Rio Cascavel, nas quais predominam os organossolos. Esses são solos turfosos, com espessuras entre $0,5 \mathrm{a}$ 3,0 metros, e nas áreas de várzeas há principalmente sedimentos aluvionares (GOMES, 2012). Portanto, características incompatíveis com a edificação, pois são áreas úmidas e inundáveis.

Somados a esses fatores físicos, outra questão que merece atenção são os resíduos sólidos domésticos e da construção civil, jogados nas ruas e/ou nos terrenos baldios. Com a chuva, estes são direcionados para as galerias pluviais obstruindo-as, e, com isso, intensificando o escoamento superficial. Há ainda o depósito destes resíduos às margens do rio, ou até mesmo dentro dele, constituindo uma barreira ao fluxo da água. Os moradores reconhecem esse problema. Na oficina de cartografia social, o Sr. Toni Sergio Guimarães, morador do bairro há 40 anos, afirmou que:

O sofrimento causado pelas inundações é antigo, as pessoas precisam se conscientizar que o lixo também é responsável pelas inundações, e precisam cuidar do bairro e depositar de maneira correta. Passa coleta três vezes por semana, não precisa jogar lixo na rua e, muito menos, no rio. Vêm pessoas de outros bairros e depositam o lixo no rio ou próximo dele.

O Sr. João Mendes de Castilho (2015) relatou que: "[...] outra forma incorreta é o depósito dos resíduos sólidos nos dutos das galerias pluviais que impede a vazão da água, provocando o escoamento superficial e potencializando as inundações".

$\mathrm{Na}$ cidade, em regra, os terrenos baldios e os fundos de vales têm sido espaços de depósito de resíduos sólidos domésticos e de materiais de construção. Em alguma medida, esta ação frequente e sem penalização leva à naturalização do problema e, consequentemente, a pouca pressão da comunidade local sobre o poder público. Na oficina de cartografia, os moradores destacaram que a prefeitura colaborou com este problema quando instalou uma caçamba de entulho muito próxima ao rio. A disposição dos resíduos em locais impróprios, além de colaborar com o problema da inundação, propaga acúmulo de moscas e causa chorume. Outro problema está relacionado à fumaça decorrente do fogo ateado por pessoas nas caçambas deixadas nos fundos de vale.

\section{OS ALAGAMENTOS E AS INUNDAÇÕES EM GUARAPUAVA E A AÇÃO DO PODER PÚBLICO MUNICIPAL}

Após as inundações ocorridas em 2014, a Defesa Civil, a pedido do Ministério da Integração Nacional-Secretaria Nacional de Defesa Civil fez um levantamento, por bairro, de todas as áreas inundáveis da cidade, para que tivessem um controle do número de 
atingidos. Nesse levantamento, apurou-se que 160 lotes foram afetados na área da planície de inundação do Rio Cascavel, no bairro Vila Carli.

Porém, por meio das ações de pesquisa, com a participação dos moradores, identificou-se 220 lotes afetados. Isso ocorreu porque a defesa civil considerou o perímetro na cota de altitude de 1013 metros, numa área de 471.524,04 metros quadrados' registrada no banco de dados cartográfico da PMG, antes da inundação de 2014, mas, por meio da pesquisa, verificou-se que naquele evento as águas alcançaram até a cota de altitude de 1015 metros, ampliando a área de inundação para 566.450,78 metros quadrados (Figura 3).

Figura 3 - Residências na área de inundação do Rio Cascavel - Vila Carli

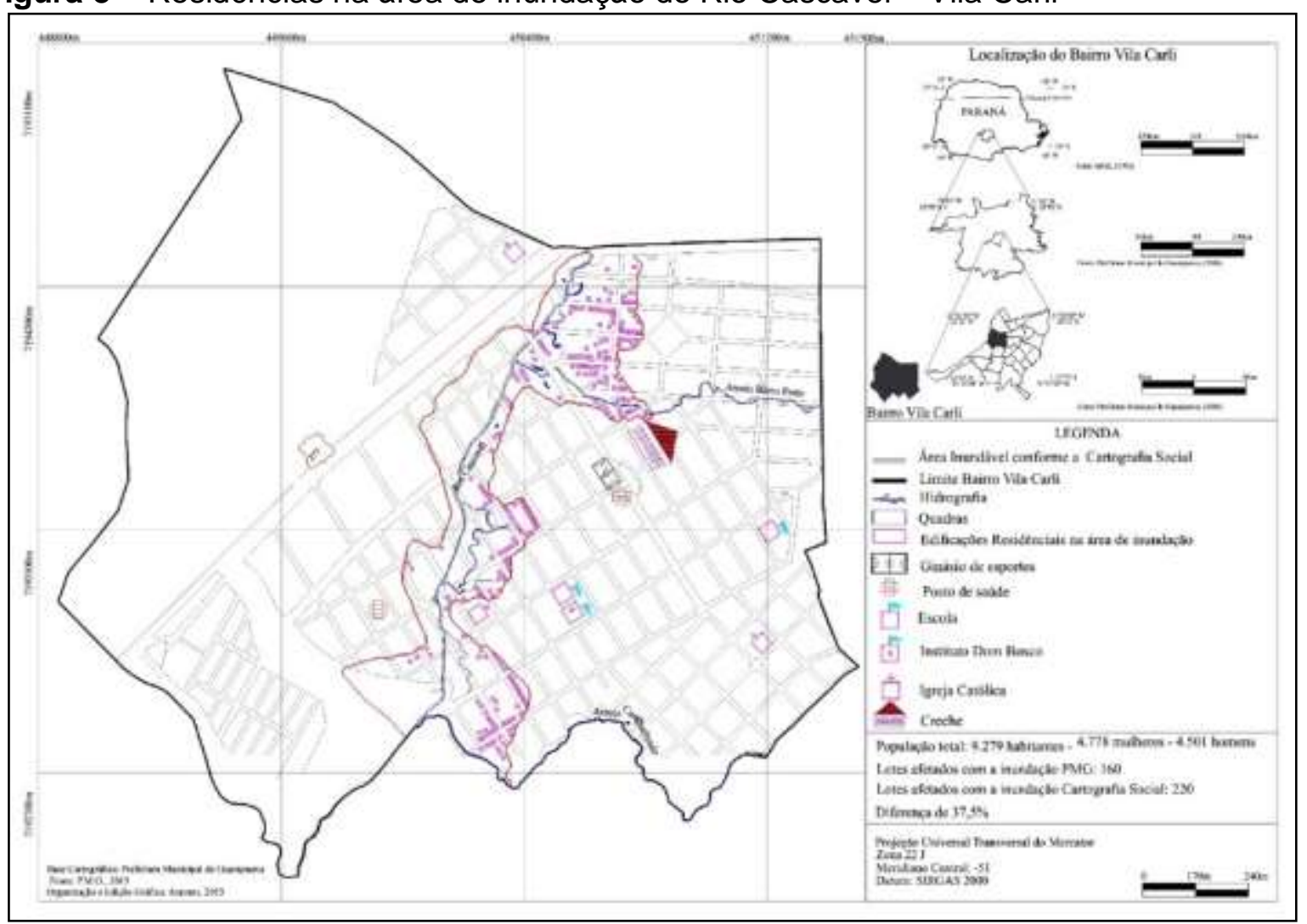

Fonte: os autores, 2015.

Em 2014 as chuvas foram intensas em todo o Paraná, com desastres em vários municípios, por isso foram emitidos pelo Governo do Estado os decretos: 11.301/2014 (PARANÁ, 2014a) e 11.303/2014 (PARANÁ, 2014b), reconhecendo a emergência das regiões afetadas e favorecendo o pedido de apoio ao Governo Federal, bem como a desburocratização para contratação de serviços de obras de emergência. Em âmbito municipal, a prefeitura emitiu o Decreto 3.923/2014, possibilitando, assim, o recebimento dos recursos e autorizando a mobilização de todos os órgãos municipais para atuarem nas ações de resposta ao desastre. 
A Cartografia Social como Processo Organizativo de Visibilidade e Mobilização Social: relato da...

Esse evento deixou dois mortos, 10 feridos, 344 desabrigados, 200 desalojados e cinco desaparecidos. Dos 344 desabrigados, 144 foram alojados na casa de familiares e amigos e o restante ficou alojado nas escolas municipais e igrejas. Em relação aos danos materiais e econômicos, destacam-se a perda de móveis, roupas e alimentos, a danificação do imóvel e de documentos, e limitações nos serviços essenciais como abastecimento de água, coleta de lixo, geração e distribuição de energia elétrica (GUARAPUAVA, 2015).

Outra medida adotada pela Prefeitura Municipal de Guarapuava foi a implementação do aluguel social através da Lei 2379/2015 (GUARAPUAVA, 2015), pela qual disponibilizou o acesso à moradia como forma emergencial e temporária, realocando 19 famílias que não puderam retornar às suas residências, uma vez que a Coordenadoria Municipal de Proteção e Defesa Civil (COMPDEC) - e a $14^{\circ}$ Coordenadoria Regional de Defesa Civil (COREDC) identificaram danos estruturais causados pela inundação. Os sujeitos atingidos de forma mais grave foram aqueles que ocupavam a planície de inundação do Rio Cascavel, como o Jardim das Américas, São Vicente/Cascavel, Vila Bela e Vila Carli (GUARAPUAVA, 2015).

Uma ação tomada recentemente pela COREDC, COMPDEC e PMG foi a elaboração de um mapa localizando os pontos que poderiam servir de abrigo (escolas, igrejas etc...), como precaução para outros eventos futuros. Outras medidas, adotadas pelo poder público, foram a limpeza e o desassoreamento do rio.

O município também institui os decretos n. 3.941/2014 (GUARAPUAVA, 2014a) e n.ำ 3.943/2014 (GUARAPUAVA, 2014b), os quais estabelecem a desapropriação de duas áreas, de 4.720, 64 metros quadrados e 43.830, 80 metros quadrados respectivamente. Ambas estão situadas no bairro Cascavel e objetivam a realocação das famílias desabrigadas, durante os eventos de 03 e 08 de junho de 2014, para a um local seguro e permanente.

Contudo, em entrevista com o então diretor do departamento habitacional da PMG, o Sr. José Edilson Silvério, identificou-se que estas áreas desapropriadas de acordo com o decreto vão atender somente as famílias que residem no Bairro Cascavel, na localidade conhecida como São Vicente. Para as pessoas que estão na área inundável do bairro Vila Carli, não existe nenhum recurso disponível, e nem data definida para resolver a questão desta população em específico.

Outra medida importante para o planejamento e gestão das áreas inundáveis é a Política Nacional de Proteção e Defesa Civil (PNPDEC), instituída pela Lei nº 12.608 de 10 de abril de 2012 (BRASIL, 2012). Esta lei apresenta os princípios, os objetivos e os instrumentos de como a gestão de riscos de desastres deve ser implementada no Brasil, com o propósito de assegurar condições sociais, econômicas e ambientais adequadas para garantir a dignidade da população e a promoção do desenvolvimento sustentável. 


\section{OS DESASTRES NATURAIS NA VILA CARLI, NA CONCEPÇÃO DOS MORADORES DO BAIRRO}

As ocorrências de alagamentos e inundações no bairro têm sido registradas há pelo menos 27 anos, entre os anos de 1989 a 2016 (GUARAPUAVA, 2016). No evento de início de junho de 2014, os processos de alagamentos e inundações, no bairro Vila Carli, foram mais intensos que os anteriores, e suas consequências atingiram um contingente maior de famílias ocasionando um grande prejuízo material (Figura 4) e surpreendendo-as com a rapidez com que a água subiu:

Quando choveu deixamos o carro aqui na rampa, porque achamos que a água não chegava, mas quando vimos, não deu tempo de tirar. O vizinho tentou proteger o carro dele colocando em um lugar mais alto, mas não resolveu. A água cobriu tudo ${ }^{4}$.

Figura 4 - Cenas da inundação no Rio Cascavel e dos desastres naturais em 2014 $\begin{array}{ll}\text { a) Vista parcial da inundação de } 2014 & \text { b) Defesa Civil resgatando moradores atingidos pela }\end{array}$ inundação

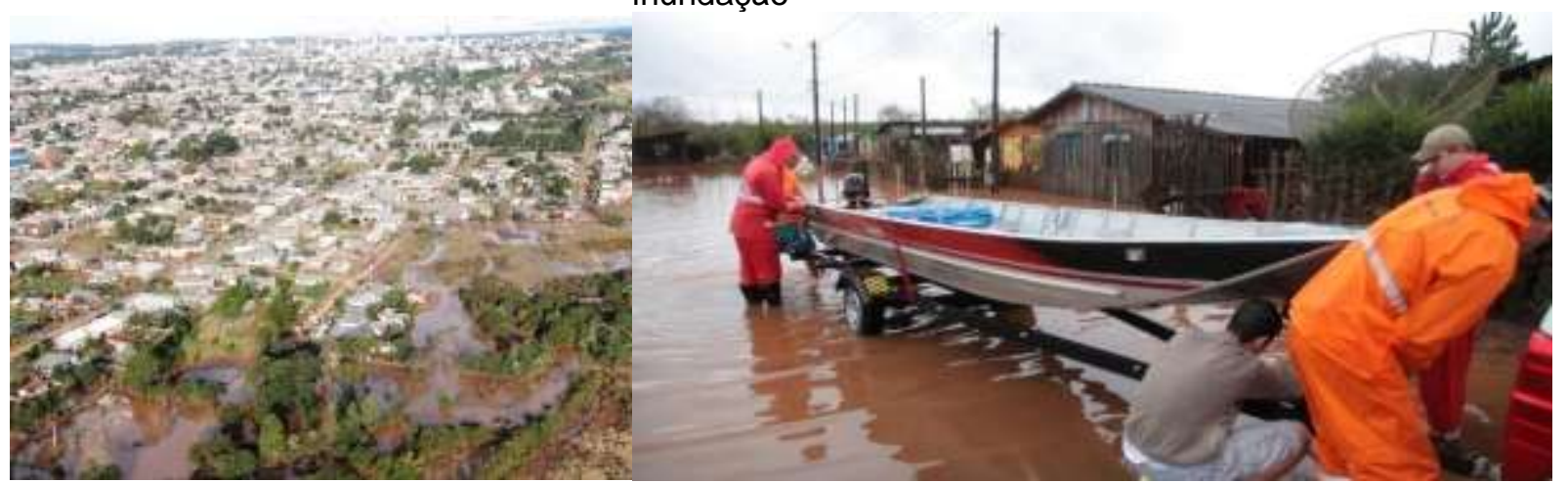

c) Moradores da Vila Carli retirando bens de casa d) Casa atinginda pela inundaçao do rio Cascavel no bairro Vial Carli

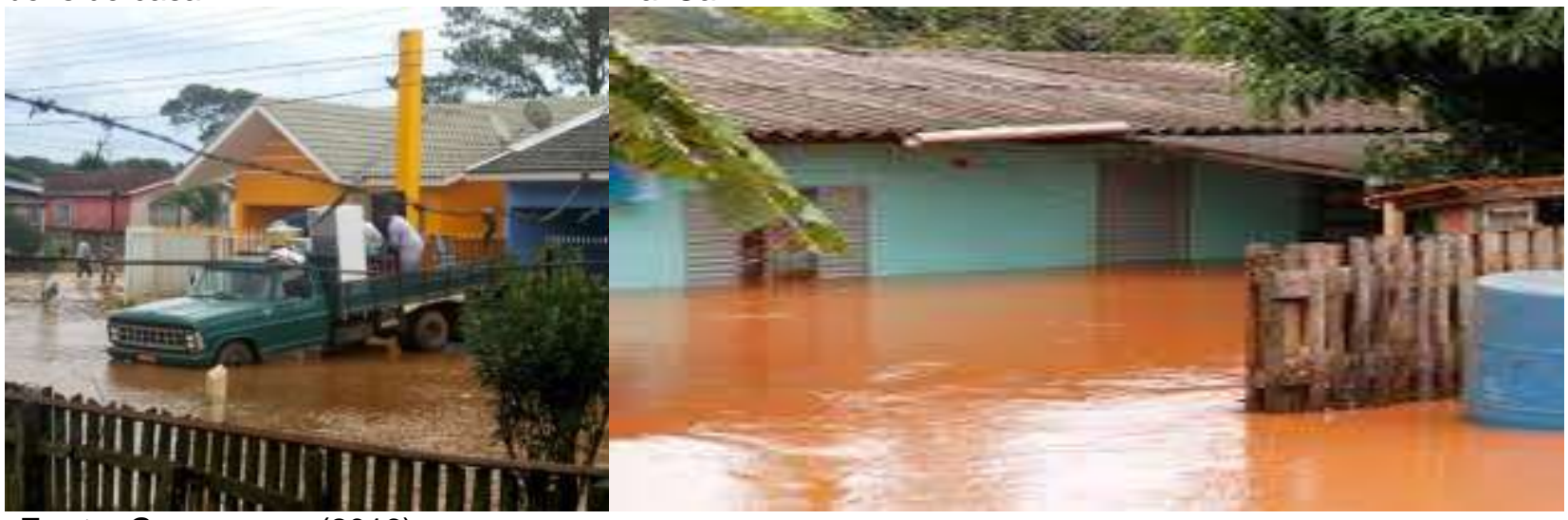

Fonte: Guarapuava (2016).

\footnotetext{
${ }^{4}$ Depoimento de Rosélia de Lima Correia, oficina de cartografia social, 2015.
} 
A Cartografia Social como Processo Organizativo de Visibilidade e Mobilização Social: relato da...

A Sra. Maria de Lima Ribeiro, também recordou o drama vivido: "Fomos visitados somente pelos bombeiros, chegaram de barco até nossa porta e pediram para nós sair da casa com urgência"

O trauma da tragédia ainda não se apagou. Depois dos eventos, a angústia permanece, pois sabem que poderão sofrer novamente com o mesmo problema. Essas lembranças são carregadas de uma grande carga emotiva e, nas oficinas de cartografia, foi um espaço de desabafo coletivo. O sofrimento vivenciado pelos atingidos pelas inundações é ainda mais problemático por não reunirem as condições necessárias para mudar para um local mais seguro e, com isso, a dependência do poder público para resolver estes problemas.

Muitos deles já tinham protocolado na PMG um pedido de solução, de indenização ou de permuta, mas não tinham tido respostas. Ao buscar informações a esses pedidos, a prefeitura informou que está previsto no cronograma atender as famílias, mas que falta recurso financeiro.

As incertezas do futuro foram recorrentes nas oficinas de cartografia. Os moradores das áreas sujeitas à inundação não sabem se serão ou não realocados, e temem que tenham que sair deste bairro para outro com menor infraestrutura. Afinal, o Bairro Vila Carli não é tão longe do centro da cidade (aproximadamente cinco quilômetros) e possui importantes equipamentos urbanos, como escolas, universidade, posto de saúde etc. Além disso, também querem um valor justo pelo seu imóvel.

Alguns deles relataram que já tinham recebido propostas para mudarem para o Loteamento Residencial 2000, um bairro popular e que fica a 5,2 quilômetros do centro da cidade, mas não aceitaram justamente porque é muito longe do centro e possui infraestrutura inferior. Outro fator é que residem no bairro há mais de 40 anos e possuem vínculos com seus vizinhos e parentes que também moram ali. Contudo, almejam que haja uma política de Estado e não só medidas paliativas em momento de tragédia como aquela de junho de 2014.

Dentre várias reclamações, uma delas diz respeito ao tratamento dado pelo poder público para com o morador da área. Argumentam que suas reivindicações não são ouvidas, justamente porque estão em áreas de inundação. A Sra. Rosélia resumiu, indignada, um dos argumentos do poder público: "Dizem que somos beneficiados porque não pagamos IPTU, é um absurdo! Queremos pagar os impostos, mas queremos solução. Não podemos viver desta forma"6.

\footnotetext{
${ }^{5}$ Oficina de cartografia social, Vila Carli, 2016.

${ }^{6}$ Rosélia de Lima Correia, oficina de cartografia social, Vila Carli, 2016.
} 
Sobre esse relato, esclarece-se que a Prefeitura Municipal de Guarapuava, através da Lei 045/2014, de 10/04/2014 (GUARAPUAVA, 2014c), alterou a redação do Artigo 138 do Código Tributário Municipal e concedeu isenção de IPTU para os imóveis localizados na faixa de inundação. E, a partir de 2014, passou a não cobrar o IPTU. Porém, embora não reconheça a área como edificável, não fez a realocação dos moradores. Outra contradição é que construções novas continuam a ser edificadas na área. Nas representações e nos relatos dos moradores, a questão da segurança e da fragilidade social foi muito marcante.

Só construí aqui porque não tinha condições financeiras de fazer em outro lugar, senão, é claro que eu queria morar no centro. Moro nos fundos da casa de meu cunhado e compramos o terreno em sociedade. É muito bom viver aqui. É sossegado, não tem roubo, a rua é calma. O único problema é quando chove. Sei que um dia vou viver com a minha família aqui mesmo no bairro, mas em um lugar livre da inundação ${ }^{7}$.

A problematização da Constituição Federal (CF) de 1988 (BRASIL, 1988), da Lei Federal 10.257/2001/Estatuto das Cidades (BRASIL, 2001), e do Plano Diretor de Guarapuava, Lei Municipal 016/2006 (GUARAPUAVA, 2006), com os moradores no bairro, durante a oficina de cartografia social, permitiu aos participantes debaterem as suas condições como cidadãos, e como podem construir demandas e lutas comuns para conquista desses direitos. Conforme o Sr. Renato Guimarães: "É importante este momento de encontro para discutir os problemas do bairro, as pessoas costumam falar entre elas, mas não existe uma discussão em grupo, acho que isso pode contribuir para a solução de alguns de nossos problemas".

Na mesma direção, o Sr. João Mendes de Castilho reforçou a importância da união dos moradores. Segundo ele: "Não aguentamos mais viver nesta angústia e incertezas, não sabemos se tudo o que ocorreu em 2014 não vai se repetir, precisamos nos unir para resolver o problema, e juntos somos mais fortes".

Verifica-se que, no momento em que as pessoas têm espaço para expor suas percepções, o direito ao território e ao ambiente, seja nos depoimentos, seja nas representações, constituem uma forma de resistência e luta ao demonstrarem o problema e reunir estratégias de organização e visibilidade. Neste contexto, conforme Vandresen (2014, p. 130) "O território, enquanto espaço de vida e de trabalho, material e simbólico, é a sua marca, e intrínseco ao seu processo de auto definição".

\footnotetext{
7 José Renato Felchak, oficina de cartografia social, 2015.

${ }^{8}$ Oficina de cartografia social, Vila Carli, 2015.

${ }^{9}$ Oficina de cartografia social, Vila Carli, 2015.
} 
A Cartografia Social como Processo Organizativo de Visibilidade e Mobilização Social: relato da...

\section{CONSIDERAÇÕES FINAIS}

A cartografia social é um processo participativo que potencializa a relação entre os sujeitos sociais e seu território e constitui-se num instrumento político de reivindicação dos direitos dos sujeitos sociais envolvidos. No âmbito deste relato de experiência, os moradores da Vila Carli, ao envolverem-se na trama de representar o modo de vida e sua relação com o território, puderam expressar como se sentem diante da violação dos seus direitos e externalizar suas angústias e demandas. A cartografia social no ambiente urbano fez emergir a discussão sobre o direito à cidade e a desigualdade ambiental.

$\mathrm{Na}$ sociedade capitalista o espaço urbano torna-se uma mercadoria, aqueles que podem pagar por um território equipado e com qualidade de serviços ocupam os melhores lugares na cidade, enquanto os que não dispõem dos mesmos recursos materiais ficam sujeitos a ocupar os espaços menos valorizados, inclusive áreas inundáveis. Neste sentido, quando o planejamento ambiental ignora essa realidade desigual, pode comprometer a justiça ambiental, pois há uma produção coletiva na cidade, mas uma apropriação desigual dos seus problemas, como consequência reforça a desigualdade ambiental, na qual está imbricada a desigualdade social e a injustiça.

No planejamento e na gestão da cidade, a cartografia, geralmente, está associada ao diagnóstico e à tomada de decisão, neste contexto a cartografia convencional tem tido um importante papel na produção de mapas com maior grau de precisão e atualização. Porém nem sempre estes avanços são acompanhados da aproximação dos sujeitos sociais que vivem a cidade. Nesse sentido, cartografias mais participativas têm um potencial maior de envolvimento do cidadão.

Nesta pesquisa verificou-se que a cartografia social, por meio de todo o processo permitiu encontros e debates coletivos, relatos e representações, proporcionou aos sujeitos, neste caso, os moradores do bairro Vila Carli, a oportunidade de expor sua visão e modo de vida no bairro e na cidade. Além disso, possibilitou a compreensão dos diferentes fatores que motivam os desastres naturais.

Nos depoimentos dos moradores pode-se perceber como a cidade é fragmentada e desigual no que diz respeito aos direitos do cidadão. Há, no próprio bairro, diferentes realidades, uma parte com e outra sem acesso aos serviços básicos e infraestrutura.

No processo de cartografia social os moradores expressaram suas demandas, suas prioridades e deram sugestões para a resolução dos problemas. Reconheceram também a necessidade de sair daquela situação e o que não aceitam é que sejam tolhidos do direito de moradia e dos serviços urbanos que necessitam. A violência e a fragilidade a que estão expostos, decorrentes das inundações, retiram a sua tranquilidade e segurança, mas a 
resistência é o único caminho que encontram para ainda viver na cidade, mesmo nestas condições.

Dessa forma, compreende-se que essa população tem resistido e defendido o direito à moradia, por meio da resistência, da articulação e da busca por fortalecimento frente aos problemas com a inundação, protocolando pedidos de indenizações, buscando informações junto aos órgãos públicos, assim como participando do processo de cartografia social.

Os resultados apontaram para a importância do processo de cartografia social como forma educativa e organizativa, na medida em que a população participa efetivamente na discussão dos problemas urbanos, na definição de prioridades, na sugestão de soluções e na mobilização de ações no bairro e traz visibilidade social.

\section{REFERÊNCIAS}

ACSELRAD, H. et al. (Org.). Guia para experiência de mapeamento comunitário. Rio de Janeiro: ETTERN, 2013.

ACSELRAD, H. Mapeamentos, identidades e territórios. In: ACSELRAD, H. (Org.). Cartografia social e dinâmicas territoriais: marcos para o debate. Rio de Janeiro: Universidade Federal do Rio de Janeiro, Instituto de Pesquisa e Planejamento Urbano e Regional, 2010. p. 9-46.

ACSELRAD, H.; VIÈGAS, R. N. Cartografias sociais e territórios : um diálogo latino americano. In: ACSELRAD, H. (Org.). Cartografia social, terra e território. Rio de Janeiro: Universidade Federal do Rio de Janeiro: Instituto de Pesquisa e Planejamento Urbano e Regional, 2013. p. 15-41.

BRASIL. Constituição (1988). Constituição da República Federativa do Brasil. Disponível em: <http:/www.planalto.gov.br/ccivil03/constituicao/constituicao.htm>. Acesso em: 5 mar. 2017.

BRASIL. Lei no $\mathbf{1 0 . 2 5 7}$ de 10 de julho de 2001. Regulamenta os arts. 182 e 183 da Constituição Federal e estabelece diretrizes gerais da política urbana e dá outras providências. Disponível em: <http:/www.planalto.gov.br/Ccivil_03/leis/EIS_2001/L10257.htm>. Acesso em: 19 abr. 2018.

BRASIL. Lei no $\mathbf{1 2 . 6 0 8}$ de $\mathbf{1 0}$ de abril de 2012. Institui a Política Nacional de Proteção e Defesa Civil - PNPDEC. Disponível em: <http:/www.planalto.gov.br/ccivil_03/_ato20112014/2012/leil12608.htm . Acesso em: 6 mar. 2018.

CANHOLI, A. P. Drenagem urbana e controle de enchentes. São Paulo: Oficina de Textos, 2005.

CORRÊA, R. L. O espaço urbano. São Paulo: Contexto, 1995.

DIAS-OLIVEIRA, E.; VESTENA, L. R. Diagnóstico ambiental da bacia hidrográfica do rio Cascavel, Guarapuava/PR. Geoingá: revista do programa de pós-graduação em geografia, Maringá, v. 5, n. 2, p. 27-47, 2013

GOERL, R. F.; KOBIYAMA, M. Considerações sobre as inundações no Brasil. In: SIMPÓSIO BRASILEIRO DE RECURSOS HÍDRICOS, 16., 2005, João Pessoa. Anais... Porto Alegre: Associação Brasileira de Recursos Hídricos, 2005. 14 p. Disponível em: <http://www.labhidro.ufsc.br/Artigos/ABRH2005_inundacoes.pdf>. Acesso em: 15 dez. 2016. 
GOMES, E. S. A dinâmica hidrológica fluvial em bacias hidrográficas com diferentes taxas de impermeabilização do solo em Guarapuava/PR. 2014. Dissertação (Mestrado em Geografia) - Universidade Estadual do Centro-Oeste, Guarapuava.

GOMES, M. F. V. B. Cartografias da paisagem: trajetória socioambiental de Guarapuava. Guarapuava: UNICENTRO, 2012.

GOMES, M. F. V. B. Desigualdade socioambiental no espaço urbano de Guarapuava. Revista RA'E GA: O Espaço Geográfico em Análise, Curitiba, n. 20, p. 95-105, 2010.

GORAYEB, A. Cartografia social e populações vulneráveis: oficina do eixo erradicação da miséria, laboratório de geoprocessamento (Lobocart). Fortaleza: UFC, 2014.

IBGE. Censo demográfico 2010: características da população e dos domicílios: resultados do universo. Rio de Janeiro, 2011.

LOBATÓN, S. B. Reflexiones sobre sistemas de información geográfica participativos (siga) y cartografía social. Cuadernos de Geografía: Revista Colombiana de Geografía, Bogotá, n. 18, p. 9-23, 2009.

NOVA CARTOGRAFIA SOCIAL DA AMAZÔNIA. Fascículos. Disponível em: <http://novacartografiasocial.com/fasciculos>. Acesso em: 6 set. 2015.

PARANÁ. Decreto oㅜ 11.301, de 09 de junho de 2014. Versa sobre a emergência e favorecendo o recebimento de recursos por parte do município. Diário Oficial do Paraná. Curitiba. Edição no 9223. p.6. Curitiba, 2014a.

Decreto $n$ ำ11.303, de 09 de junho de 2014. Versa sobre a emergência e favorecendo o recebimento de recursos por parte do município. Diário Oficial do Paraná. Curitiba. Edição no 9223. p.7 Curitiba, 2014b.

GUARAPUAVA. Prefeitura Municipal. Coordenadoria Municipal de Defesa Civil de Guarapuava (COMPDEC). Mapeamento de áreas com risco de inundações do Rio Cascavel e seus afluentes no município de Guarapuava - Paraná: relatório final. Guarapuava, 2015.

GUARAPUAVA. Prefeitura Municipal. Decreto nㅜ 3923/2014. Declara emergência nas áreas do Município de Guarapuava - Estado do Paraná, afetadas por alagamentos - conforme IN/MI 01/2012, item 1.3.2.1.4. Boletim Oficial do Município, Guarapuava, ano 19, n. 926, 8 jun. 2014a.

GUARAPUAVA. Prefeitura Municipal. Decreto no 3941/2014. Declara de Utilidade Pública para fins de Desapropriação e de Relevante Interesse Social, o imóvel que menciona e específica e dá outras providências. Boletim Oficial do Município, Guarapuava, ano 19, n. 927, 17 jun. 2014b.

GUARAPUAVA. Prefeitura Municipal. Lei complementar $n^{\circ}$ 016, de 4 de outubro de 2006. Dispõe sobre o Plano Diretor do Município de Guarapuava, atendendo às disposições do Estatuto da Cidade - Lei Federal n.. 10.257/01 e Lei Estadual n.. 15.229/06 que dispõe sobre o conteúdo mínimo dos Planos Diretores Municipais, bem como revoga a Lei Municipal n. 1.101/2001, de 28.12.2001, que instituiu o Plano Diretor de Guarapuava. Disponível em: <https//leismunicipais.com.br/a/pr/g/guarapuavalei-complementar/2006/1/16/lei-complementarn-16-2006-dispoe-sobre-o-plano-diretor-do-municipio-de-guarapuava-atendendo-as-disposicoes-do-estatuto-dacidade-lei-federal-n-10257-01-eleiestadual-n-15-229-06-que-dispoe-sobre-o-conteudo-minimo-dos-planosdiretores-municipais-bem-como-revoga-a-lei-municipal-n-1101-2001-de-28-12-2001-que-instituiu-o-plano-diretordeguarapuava>. Acesso em: 19 abr. 2018.

GUARAPUAVA. Prefeitura Municipal. Lei complementar no 045, de 10 de abril de 2014. Altera e dá nova redação ao Art. 138 e acrescenta a alínea a ao $\S 6^{\circ}$ do Art. 96 da Lei Municipal nº.1.108/2001 - Código Tributário Municipal - e dá outras providências. 2014c. 
Disponível em:

< http://www.pmg.pr.gov.br/legislacao/arquivos/2014/lei\%20complementar\%20n\%20045\%202014\%20\%20-

\%20nova\%20redacao\%20ao\%20art138\%20do\%20codigo\%20tributario\%20-

\%20isencao\%20iptu\%20horta.pdts Acesso em: 15 jan. 2016.

GUARAPUAVA. Prefeitura Municipal. Publica imagens, dados e informações sobre a gestão do município de Guarapuava. Disponível em: <http://www.guarapuava.pr.gov.br/>. Acesso em: 12 jul. 2016.

RIGHI, C. A. Impacto do crescimento urbano em uma bacia hidrográfica na cidade de Guarapuava. 2003. Trabalho de Conclusão de Curso (Graduação em Geografia) UNICENTRO, Guarapuava.

SILVA, L. F. Cartografia social no planejamento ambiental: estudo de caso em área de inundação do Rio Cascavel na cidade de Guarapuava-PR. 2016. Dissertação (Mestrado em Geografia) - Universidade Estadual do Centro-Oeste, Guarapuava, 2016.

VANDRESEN, J. C. Povos e comunidades tradicionais em unidades de conservação: a cartografia social como instrumento de mobilização dos llhéus do Rio Paraná. 2014.

Dissertação (Mestrado) - Universidade Estadual do Centro-Oeste, Guarapuava.

VESTENA, L. R. Desnaturalização dos desastres: em busca de comunidades resilientes. Curitiba: CRV, 2016.

VESTENA, L. R. et. al. Percepção ambiental sobre as causas das inundações, Guarapuava/PR: em busca da cidade resiliente. Revista do Departamento de Geografia, São Paulo, v. 28, p. 280-294, 2014. Disponível em:

<http://www.revistas.usp.br/rdg/article/view/90016>. Acesso em: 12 out. 2016.

Recebido: abril de 2017. Aceito: abril de 2018. 